\title{
Trends and Challenges of Educational System in the XXI Century
}

\author{
Madina Serikbekovna Ashilova ${ }^{1} \&$ Kalimash Kapsamarovna Begalinova ${ }^{2}$ \\ ${ }^{1}$ Kazakh Ablai Khan University of International Relations and World Languages, Republic of Kazakhstan \\ ${ }^{2}$ Kazakh National Technical University after K.I Satpayev, Republic of Kazakhstan \\ Correspondence: Madina Serikbekovna Ashilova, Kazakh Ablai Khan University of International Relations and \\ World Languages, Kazakhstan, 050001, Almaty, Muratbayev Street, 200, Republic of Kazakhstan. E-mail: \\ alibek557@inbox.ru
}

Received: June 30, 2014 Accepted: July 28, 2014 Online Published: September 28, 2014

doi:10.5539/ass.v10n20p225 URL: http://dx.doi.org/10.5539/ass.v10n20p225

\begin{abstract}
This article specifies the main challenges and trends of the modern educational system. It addresses the most pressing educational issues, such as consumerization of modern education, exteriorization of education (transformation of knowledge into information), increase of earthliness and immorality under the conditions of development of consumer society, entertainment and generality, mass character of culture. The author sees the main cause of the crisis in the dominance of Western exploitative attitude towards the nature and people, and western type of education being produced on its basis. Accordingly, the main way out of this situation-an appeal to the Eastern system of upbringing-education cultivating nature and harmonious attitude of a man to it, setting up of fruitful and equal dialogue between the cultures for the purpose of humanization of the modern education. Main goal of research is to give a coherent understanding of the correlation of educational philosophy and philosophy of the western and eastern culture, and to offer the author approach to the social and philosophical understanding of basic scientific definitions of the problem. Main conclusions: the spiritual change of the society means changing of its foundations. Unfortunately, the growing influence of West and Western European education does not imply growth of humanization. On the contrary, the humanization comes from eastern countries. And perhaps through the establishment of intercultural dialogue, the trend in education may become the main.
\end{abstract}

Keywords: philosophy of education, East-West, globalization, fundamentalization, humanization, environmentalization

\section{Introduction}

In the XX century, education has become a very important spheres of human activity. This century is marked by great achievements in the field of education, which formed the basis of a huge social changes, and scientific and technological progress. Only in a few decades after the war, in the educational system in the world there were trained more people than in all previous human history. However, the rapid expansion of education and change of its status in the XX century was accompanied by a worsening of problems in this area, which allowed some researchers to make and justify the conclusion on global crisis in education, the source of which, of course, is the anthropological crisis, the crisis of a man himself. Educational problems turned out to be the center of public attention. Significance of research of the state and prospects of education is increasing, as it is realized that to solve the challenges of global problems confronting the humanity there should be some new creative force, the source of which is the human potential of society. "It is necessary to create the uniform worldview system with a new interpretation of fundamental concepts of existence and consciousness, world and man. On this basis only it is possible to create the universal philosophy of education which will ensure the right impulse for educational reforms, bring back original objectives of education, i.e. formation of responsible and moral personality included in the past, present and future culture of humanity" (Nalivaiko \& Ushakova, 2010).

The need to study the specifics of modern education, the relationship of Western and Eastern educational systems is due to serious problems that exist in these areas. First, lack of proper fundamentalization of education; second, a tendency of significant reduction in humanization of education and science; environmentalization of education is missing in the modern conditions of co-evolutionary development of society. Therefore, "we must all together make a forecast, not in-house forecast on how the education will be developed, but a forecast on how 
the country will be developed. And within this forecast, we must determine what we should do for its development. It is absolutely clear that these challenges cannot be solved without closer cooperation between the educational system and science. This is not an artificial union, this is the only possible step, and thus the union should be aimed at specific result" (Fursenko, 2004).

As never before, the education of the XX and XXI centuries has demonstrated that it can play a significant role in the socio-economic, political and spiritual life of society, if it becomes an internal need of the human being, an important aspect of his essence. "New Century identified new paradigms and trends in the development of education as well. First of all, it should be noted that UNESCO called psychology the scientific paradigm of the XXI century. And this, in turn, allows us calling humanization and humanitarization of the whole educational process the most important paradigm of education in XXI century" (Begalinova, 2012).

Globalization, in turn, as the leading trend of our time just promotes separation of education from a man himself, it takes a form of an independent existence, regardless of the subject, carrier of education, which has an adverse effect on the formation of the subject of education and formation of a man. The contradiction of modern education, the crisis phenomena of universal culture demonstrate that this crisis can only be removed through the union, the ratio of the Eastern and the Western ways of thinking, civilizations. No introduction of information technologies into education in the modern India or China will lead to a qualitative change in these countries. This innovative technology must be harmonized with the specific nature of each country, especially countries of the Eastern and Eurasian civilizations.

In turn the crisis which education and culture of the West is undergoing can be overcome through a combination of Eastern and Western educational trends, since the West is more inclined to technicalization, technical, rational understanding of the world, and the East-to intuitive and sensitive comprehension of the world. These two trends have to be connected in education. How to reconcile these opposing trends? This is referred to in this article.

\section{The Main Problems of Modern Education}

XXI century was marked by a transition to a qualitatively different state of life. Coincidentally, at the turn of the centuries and millenniums, the humanity has entered a new age-the information age. Agrarian and industrial age gave place to the "third wave"-the post-industrial, the main components of which became the market economy, development of open democratic societies, and widespread introduction of means of communication, Internet and computer technologies. According to forecasts of scientists and theorists of the information age (Toffler et al., n. d.), in the XXI century, the major corporations will certainly give place to the universities, and businessmen-to the scientists and professional experts. Education as access and acquisition of the vital and necessary information will be the engine of both science and economy and future of the countries. And this, according to the number of scientists-is the natural result of centuries-long development of the theory of education. If in "Aristotle time, the theory of education was considered as a method of lifestyle and looked for the facts for facts and was associated with the social and natural aspects of life, then in the times of Newton's theory, the education was associated with the division between the theory and practice, and the methodology was of considerable importance. In the days of quantum theory, the features of the theory of education of Aristotle and Newton times have been changed a lot, and such functions as the integration between the theory and practice and pluralism, and so on were the dominant one" (Salahshoori \& Yousefzadeh, 2014). In this regard, the educational system has a special role-to prepare highly educated, competitive professionals with a huge set of various competencies, knowledge and skills.

However, there are many problems in the modern education as well. Not coincidentally, in the recent years, scientists have more to say about the crisis in education, which is a direct consequence of the widespread decline of culture, spirituality, anthropological crisis and worsening of the global environmental problems. Education is increasingly involved in the market relations, becoming an integral part of the "consumption society" and consumerism. Not only the ways of information presenting, the role of student and teacher, educational methods are changing, but the knowledge itself is changing and transforming. It is very different from the knowledge of previous ages. This is the knowledge-information. According to the opinion of French philosopher J. F. Liotar, it certainly should be translatable into the language of machines in the amount of information, should be operational and even transportable through the channels. No matter how we call this knowledge today-"the most significant rate in global competition for power" (Liotar, n. d.), or simply the "information product", it is spiritless and immoral! And, above all, that is the education which is responsible for all the problems and threats to the man, society and nature. Because it prepares one-dimensional man, extremely narrow specialist, thinking only about the economic profit and personal gain, and not thinking about the consequences of his activity. Setting "to be in order to have" is successfully implemented by the modern man. And this phenomenon is related not to one or two countries. In pursuit of profit, and under the conditions of global competition for power, this 
phenomenon has become widespread. However, such a situation will not last for a long time. Man cannot endlessly exploit the nature, use its resources with no limits and force the others to do so. It is fraught with serious consequences. Is it possible to have some compensations of practical or moral and spiritual kind in the field of education? Neither the market prosperity, nor the formal right, nor the supreme synthesis of all the problems and their solutions in the field of education, nor the globalization are such compensations.

\section{The Origins of the Crisis}

In this connection it should be noted that the setting "to have" or "to possess", in other words, a consumer attitude to the nature and other cultures is the characteristic feature of the Western European culture only, the East originally lived on the principle of "to be" or the principle of harmonious unity with the nature. The well-known orientalist Grigorieva, comparing the Western and Eastern cultures, argues that these settings are primordial and can already be found in the myths of the two different types of cultures. For example, in the work "Tao and Logos," she considers the Greek myth of the initial chaos. If pre-basis of the world is chaotic, incoherent and dangerously direful, then the ancient Greeks believed that it is necessary to change it and get rid of the chaos. This gave them the right to start rebuilding of the world, to create order and Cosmos. Belief in the efficacy of "struggle" with the original nature or Chaos as a way of solving problems has become the norm and for thousands of years simulated the behavior of the Europeans. This is the Western paradigm and Western way of attitude to nature. Already in the middle of the last century, with the first reports of the Club of Rome, it became clear that it would inevitably lead to a global catastrophe.

If to talk about the same pre-basis of the world continues Grigorieva, then in Eastern philosophy there is also a representation of the primordial Chaos. But this Chaos is completely different. It's not awesome, not overpowering, but on the contrary-it is a perfect Chaos, led by the most heaven will, dharma or tao. The Chinese call it Hun Dun-chaotic order or good disorder, which is taken as a sample and paradigm of all. There's even such a parable: Rashness and Recklessness wanted to turn their friend Chaos into a man and drilled seven holes in him (ears, eyes, nose and mouth). One hole per day. On day 7, Chaos died ... This parable suggests that the subjective intervention in nature violates its natural course, the law of things and always leads to their death. The myth of Chaos appeared among the Taoists in the VI century BC! But how relevant it is today, isn't it? (Grigoriyeva, 1992).

Oriental style of thinking refers to the spiritual dimension of a man. Its purpose is to reveal the deep layers of the human psyche. While the western style is focused on outward direction, on a rational understanding of the world. Its main tool is the mind, the rational.

If the eastern philosophy is associated with the inner world of a man, with his spirituality, the western directs all its energy on improving the external world, acting as a subject of material and practical activities. This explains why credo of K. Marx is represented in the words: "The philosophers interpreted the world just in various ways, but the point is to change it" (Marx \& Engels, 1962). And Lao-tzu and other eastern sages write that before to change the world, change one.

The basis for the Eastern type of education is a non-dual model of the world-this is that. For the Western one it is dualism (either this or that). If the East has made as the central theme of its research-the problem of a man, that the western philosophy has many aspects. It studies the problems of natural philosophy, ontology, epistemology, methodology, aesthetics, logic, etc. It is necessary to note one very important feature of the eastern philosophy-its relationship with mysticism and religion. Often, the philosophies of the eastern countries are formed and developed in the framework of some religious tradition (Hinduism, Buddhism, Islam, etc.). Thus, the world outlook basis of pedagogical tradition of the South Asian civilization was Hinduism and later Buddhism. And this basis defined the way of life of a man, system of social and ethical norms, rituals and celebrations. Neither upbringing nor education was considered to be all-powerful. Inherited qualities and hereditary within this tradition fully conditioned the possibilities of upbringing and education in the process of human development (Rean, 2002).

At the heart of the 'Eastern type of education' there lie the philosophical traditions of East. They are characterized by such features as conservatism, traditionalism, and strict adherence to rules, regulations and canons. 'Western type of education' is more liberal. It is characterized by the desire to pursue a free search for truth, comprehension of the world, while it is not confined to one religious system or philosophical doctrine. It embraces multiple aspects, and may also be atheistic. The famous Russian philosopher, N. Y. Danilevsky, has perfectly described the difference between two very different types of worldview: N. Y. Danilevsky gave his own assessment of these two very different types of world perspective: "West and East, Europe and Asia are presented to our minds as some opposites, polarities. West, Europe constitute a pole of progress, continuous improvement, 
continuous movement forward; East Asia-a pole of stagnation so hateful to the modern man ... if not the West, so East, not Europe, so Asia-there is no middle" (Danilevsky, 1991). Often, East and West are represented in the research literature as binary oppositions: tradition-innovation, spirituality-materiality, collectivism-individuality and others.

Nevertheless, today East and West are not opposed to each other as before. On the contrary, they are looking for common ground in order to establish a fruitful dialogue between each other. "The meeting of the West with the East is largely dependent on the ability of both sides to understand each other," says Heinrich Dumoulin. The most important condition for a dialogue is desire, the desire of each of the parties to cooperate: to strive to understand the other, deepening the understanding of oneself; to try to understand the other, prompting the other to return understanding (Semenov, 2004).

Not only East needs a civilized and successful experience of West, but also West needs the eastern one. Today it is extremely obvious. The time has come when humanity was faced with the pressing need to change the strategy of its development, to change attitudes towards themselves and the world. This is the moment when the further exploitation of nature and human resources is no longer possible, the moment, when minor problems of a seemingly local character quickly develop into global ones, solvable only by the joint efforts of many countries. There is a need for drastic revaluation of all values. In this regard, Western technocratism, which was once a key to a successful development, has become an insurmountable obstacle today. It can only be overcome by the introduction to the Eastern spirituality and culture. East, through its commitment to traditions, has managed to keep a reverent attitude to the spiritual, sacred, sacral. And in the light of contemporary issues it favorably distinguishes its worldview. So, V. Schubart wrote raising the question of the relationship between East and West that "in order to understand the relationships and dependencies between the East and the West in all their significance, the problem should be put in the broader framework of existence. In other words-it is to be associated with the deep questions of human existence. In other words-it should make the subject of philosophy "(Semenov, 2004). German professor Von Rintelen believes that in order to establish a dialogue, the East and the West must 1) maintain the allegiance and respect to a different culture; 2) their rapprochement is possible in the field of philosophy in which the culture of the people is expressed to the greatest possible extent; 3 ) the exchange of ideas should be associated with the values of different cultures; 4) that should be an object of a personal experience that is possible only in the rejection of own prejudices and understanding a different culture in its entirety; 5) when there are differences in values, you can find some common features for different cultures; 6) consider the values not as implemented, but consider each case as a way to express the timeless core values; 7) only in the sphere of values it is possible to achieve mutual understanding, because in them a man can open himself to the maximum fullness (Semenov, 2004).

At the end of the twentieth century the problem of the relationship between East and West became so urgent that resulted in a separate branch of philosophical research-comparative philosophy. This branch deals with the study of methodological and philosophical foundations in order to synthesize the various philosophical systems, but at the same time preserving the national and distinctive style of thinking of each one. The main method of the comparativist philosophers is the method of comparison. ... According to the Indian philosopher P. T. Raju, the object of study of East and West are philosophical systems, as they set different values. The Indian philosopher believes that West has cultivated a 'male', urban, technological way of being. While East has created a 'female', agrarian, philosophic one. The two of these ways of being need to be merged, taking the best possible qualities from the both. According to the philosopher, it is also necessary to practice yoga, because in this case philosophy will be able to team up with religion to seek and reveal the truth, and uncover the truth in human activities (as in China), focus on the mystical experience and learn the existential approach to the problems of the human world (Northrop) (Kolesnikov, 2003). In the comparative philosophy, there are two main approaches-analytical and synthetic. Analytical approach involves consideration of the philosophical and cultural traditions, identification of ways and opportunities for dialogue and synthetic-compares them, compares methods and ideas in the historical development of this concept, and in the collision and confrontation between the different traditions (Kolesnikov, 2004).

Today, not only for Russia and Kazakhstan, but also for other CIS countries there are questions of: is it possible to take as a kind of ideal the Western educational experience, or on the contrary, it must be checked by being exposed to a sharp criticism? Which path Russia and Kazakhstan would choose in the future for further development-eastern or western? And what are in general the paths of world civilization? (Lavrynenko, 2004). Eastern and western cultures met in our countries long before the occurrence of these issues. It can be said that a mixed multi-ethnic society has been formed in our countries, which has in their foundations both the western and eastern samples. That is why Russia, Kazakhstan and other countries of post-Soviet space should learn human 
values through in-depth study of cultures of their own nations (Lavrynenko, 2004).

Modern education is a complex process of human evolution. Education is also a continuous dialogue between cultures because it acquaints a student with their own cultural norms, patterns of behavior, senses and knowable systems, but also "alien" one. Russian philosopher Y. V. Ilyenkov noted that East and West are different not because they are located on opposite sides from Elbe or Berlin Wall. These are not geographical concepts. The border between East and West goes on a much deeper level-through the heart of contemporary culture, "not coinciding at all with the geographical boundaries and political boundaries of the modern world. It runs not only between the parties within the same country, but often even through the mind and heart of one and the same person" (Ilienkov, 1991). Modern philosophers actualize the problems of East and West, are looking for points of contact of different cultures, including opportunities for dialogue between East and West in matters of education and upbringing.

In this regard, the position of the modern Indian philosopher S. N. Balagangadhara expressed by him in the theory of learning configurations is quite interesting. It is based on an understanding of culture as a tradition that can be seen "as a certain form of learning and meta- learning" (Balagangadhara, 1994). In the form there usually predominates one type of knowledge. However, the philosopher writes, it does not mean the absence or failure of the other forms. Comparing Eastern and Western types of pedagogy, Balagangadhara highlights two very different teaching cultures. Western is the theory-oriented learning, its students 'act to know', and eastern one-the performativity-oriented learning, its students 'know to act' (Oord, 2007).

The relevance of the dialogue between East and the West increases as contradictions of modern civilization and global problems are growing. A lot of western and eastern scholars recognize the need of a deep awareness of these problems, refusal from the non-purely man-made mode of life, the transition to a more loyal methods combining eastern wisdom as well. About his, in particular, is written by American thinker Samuel Huntington. In the concept 'clash of civilizations', he suggests West to 'adapt' to the other civilizations, the influence and power of which increase with each passing year. He also encourages a deeply grasp their religion and culture, because, in his opinion, "no universal civilization is expected in the foreseeable future, but the world of different civilizations, each of which will have to learn to exist with others" (Huntington, 1996).

Thus, the emergence of a global philosophy is now no longer a single line, one-sided process, representing the interests of only one country or group of countries. The global philosophy must proceed from the interests of all cultures, civilizations, offering universal spiritual systems that will allow it to develop further and more importantly-make faceless, soulless humanity humane again.

\section{Specifics of the Eastern Upbringing and Educational System}

Education as we know consists of two processes: the process of learning and process of upbringing. In the West the priority is given to learning, the sphere of upbringing is replaced over time. In the East, on the contrary, the priority was initially given to the process of upbringing. Here are some features of the Eastern education: the inseparability of subject and object, man and nature, student and teacher; focus on the spiritual result and moral self-perfection of a man, as opposed to the Western system of education which is focused on practical result; inextricable connection of educational system with economic and social development of the country; the main purpose of teacher-upbringing of the "citizen" (with strict self-control and self-awareness skills); versatility of educational program. The most important, of course, is the priority of upbringing which today makes the educational system the attractive one.

Oriental type of education is characterized by many features, among which traditionalism, conservatism, continuity of knowledge; preservation and transmission of ancestral knowledge clearly stand out the most. These features are negative in West. Traditions represent something obsolete, past, irrelevant to a western person. In East, traditions are an integral part of the culture; they are a particular historical reality, 'a spiritual assimilation of a student by a teacher'. Discovering them and associating themselves with ancient traditions eastern man aspires to self-realization and enlightenment.

In general, the history of civilizations, as well as contemporary processes of social development suggest that in fact there are not many different human societies with closed systems of cultures and philosophies, but one single universal culture. Accordingly, there is one single global educational space. However, developing in various parts of the world, it creates different variations and forms, making it ethnically rich, multivariate and diverse.

However, globalization and the global labor market impose uniform requirements on both Western and Eastern types of education. The primary objective of modern education is to train highly qualified professionals. This 
requirement is enhanced in the early 21 st century. Despite the similarity of tasks, eastern education has managed to preserve its anthropological nature. One of its features was the formulation of the philosophical problems in the form of prescription structures. So, for example, in Islamic countries to this day, "based on a holistic philosophy, a man is regarded as a part of nature. The concept of sustainability, which includes aspects of emotions, spirit, intuitions and imaginations of a man, is also in a focus in Islamic philosophy of education. This philosophy also focuses on the concept that every aspect is simultaneously interrelated (connected by reality). From the perspective of the curriculum, the subject of Islamic education is introduced from the Islamic philosophy of education, and it is a comprehensive and integrative. Variety of aspects is taught through this subject, including the method of practice to enable students to think and solve problems based on the Koran"(Hassan et al., 2013).Succession, traditional, anthropological and prescribed character affected the entire Eastern educational system, and they permeate all forms of education. The Western educational system lays less emphasis on the human nature of education, on the fact that a student himself as an object of education occupies some place in the education.

The main objective of education-is the transfer of knowledge from teacher to student. However, since the 20th century priorities begin to change in western education. The role of the student in the learning process increases. The transition to new technologies and teaching methods, the introduction of the credit system, etc. enhances this process. A student now becomes a full subject of the pedagogical process. "Designing a balanced curriculum that can bring the school and university trajectory in line with the natural and artificial environment-they are a part of this moment, meaning that success, mobility, dynamism, constructivism and sense of duty may become the major advantages for the prevalence at a labor market in the near future"(Barna et al., 2013).

XXI century begins to abandon the Prussian educational system, wherein the teacher took the major place, and the main attention was paid to the teacher. Credit system of education, active forms, adoption of the Eastern samples of upbringing- education will promote further disclosure of student's capabilities, deeper involvement in the educational process.

\section{Conclusion}

During the analysis of Western and Eastern models of philosophizing, the challenges of globalization, as well as Western and Eastern educational systems, the author came to the conclusion that the principle of unity of common and single, national and global cannot be considered any more in one version only, as it was suggested in Marxist-Leninist dialectics. In fact (it is finely demonstrated by the genesis of the eastern and western education systems) a unit, which is represented by a particular ethnic group, nation, culture, may be more significant than the total. The dialectics of this process is such that over time single can grow into plural and even more than that-to become universal. Thus, the educational system, which has developed in Western Europe, was originally inherent only in this region, being local. However today, thanks to globalization, scientific and technological progress and enhanced international cooperation, it has become global and of a global nature. Unfortunately, the growing influence of West and Western European education does not imply growth of humanization. On the contrary, the humanization comes from eastern countries. And perhaps through the establishment of intercultural dialogue, the trend in education may become the main.

\section{References}

Balagangadhara, S. (1994). The "Heathen in his blindness". Asia, the West and the dynamic of religion (p. 563). Leiden: E.J. Brill.

Begalinova, K. (2012). Education as a socio-cultural phenomenon. Journal of philosophy of education, 6(45), 161-169.

Danilevsky, N. (1991). Russia and Europe (p. 212). The Book.

Fursenko, A. (2004). Education and science in Russia facing a new choice. Research Universities (pp. 17-19). Integration of science and education, Tverskoy Innovative Center.

Golosov, G., \& Galkina, L. (1997). Modern Comparative Politics: A Reader (p. 378). Moscow Public Science Foundation.

Grigoriyeva, T. (1992). Tao and logos (p. 380). Publishing firm "Eastern literature" RAS.

Huntington, S. (1996). The clash of civilizations and the remaking of world order (p. 367). New York: Simon and Schuster.

Ilienkov, E. (1991). Marx and the Western World (p. 464). Politizdat.

Kolesnikov, A. (2003). The logic and methodology of comparative philosophy (pp. 3-11). Publishing House of St. 
Petersburg State University.

Kolesnikov, A. (2004). Comparative Philosophy: East-West (p. 386). Publishing House of St. Petersburg State University.

Lavrynenko, V. (2004). Philosophy (p. 511). Lawyers.

Linguistic orientation and methodological perspectives in the philosophy of the contemporary education. (2013). Retrieved December 23, 2013, from http://www.sciencedirect.com/science/article/pii/S1877042812026341

Marx, K., \& Engels, F. (1962). Theses on Feuerbach. Politizdat, 154.

Nalivaiko, N., \& Ushakova, E. (2010). On the role of education in the society of the XXI century. Journal of philosophy of education, 1(30), 71-79.

Oord, L. (2007). To westernize the nations? An analysis of the international baccalaureate's philosophy of education. Cambridge journal of education, 37(3), 375-390. http://dx.doi.org/10.1080/03057640701546680

Rean, A. (2002). Psihology and education (p. 332). St. Petersburg University Press.

Semenov, N. (2000). East and West: The two types of historical consciousness (p. 48). St. Petersburg Philosophical Society.

Semenov, N. (2004). Philosophical traditions of the East: Studies (p. 304). Yerevan State University.

Study of educational theory evolution from ancient until today. (2014). Retrieved January 5, 2014, from http://www.sciencedirect.com/science/article/pii/S1877042812017466

The role of Islamic philosophy of education in aspiring holistic learning. (2013). Retrieved December 29, 2013, from http://www.sciencedirect.com/science/article/pii/S1877042810017970

\section{Copyrights}

Copyright for this article is retained by the author(s), with first publication rights granted to the journal.

This is an open-access article distributed under the terms and conditions of the Creative Commons Attribution license (http://creativecommons.org/licenses/by/3.0/). 